\title{
ANALISIS STRATEGI PEMASARAN UNTUK MENINGKATKAN KEUNGGULAN BERSAING (Markerting Strategy Analysis To Improve Competitive Advantage)
}

\author{
Ratna Ekasari, Rodih, Rezki Aulia Pramudita
}

Prodi S1 Manajemen, ratna_ekasari@dosen.umaha.ac.id

Info Artikel

Diterima Februai 1, 2021

Direvisi Februari 20, 2021

Dipubikasi Maret 20, 2021

\section{Kata Kunci:}

Strategi pemasaran, keunggulan bersaing.

\begin{abstract}
Abstrak
Perkembangan industry makanan dan minuman di Indonesia yang semakin meningkat pada setiap tahunnya menciptakan persaingan yang ketat untuk mempertahankan atau pun meningkatkan pasar PT.Fastrata Buana merupakan salah satu perusahaan distribusi yang telah berhasil memasarkan produknya di seluruh Indonesia. Penelitian ini bertujuan untuk mengetahui strategi yang selama ini digunakan oleh perusahaan untuk meningkatkan volume penjualan. Selain itu analisis ini juga bertujuan untuk mengetahui langkah-langkah strategis yang sebaiknya diterapkan oleh perusahaan untuk kedepannya agar dapat bersaing dengan kompetitornya. Penelitian ini menggunkan metode penelitian kualitatif yaitu mencari informasi atau wawancara kepada narasumber di PT. Fastrata Buana Cabang Krian Sidoarjo. Hasil analisis penelitian yang dilakukan, peusahaan disarankan untuk lebih mengembangkan pemerataan pasar sebagai strategi alternatifnya. Dan selalu mengedepankan loyalitas konsumen seprti sopan santun dan ramah. Perusahaan diharapkan dapat mempertimbangkan penerapan strategi ini sehingga dapat memperkuat posisi bersaing berusahaan PT. FastarataBuana yang dijalaninya semakin maju dan berkembang. Kata Kunci :Strategi pemasaran, keunggulan bersaing.
\end{abstract}


Keywords :

Marketing strategy, competitive advantage

\begin{abstract}
The development of the food and beverage industry in Indonesia which is increasing every year creates intense competition to maintain or improve the market of PT. FastrataBuana is one distribution company that has successfully marketed its products throughout Indonesia. This study aims to determine the strategies that have been used by companies to increase sales volume. In addition, this analysis also aims to find out the strategic steps that should be applied by the company in the future in order to compete with its competitors. This study uses qualitative research methods, namely seeking information or interviews with speakers at PT. FastrataBuanaKrianSidoarjo Branch. The results of the analysis of research conducted, companies are advised to further develop market equity as an alternative strategy. And always prioritize consumer loyalty like courtesy and friendliness. The company is expected to consider implementing this strategy so that it can strengthen its competitive position in the PT. FastarataBuana, which he is currently progressing and developing.
\end{abstract}

\section{PENDAHULUAN}

Bisnis (business) tidak terlepas dari aktivitas produksi, pembelian, penjualan, maupun pertukaran barang dan jasa yang melibatkan orang atau perusahaan. Aktivitas bisnis pada umumnya mempunyai tujuan menghasilkan laba, serta mengumpulkan cukup 
dana bagi kegiatan bisnis itu sendiri. Bisnis tidak akan berjalan dengan baik jika tidak di dukung dengan strategi bersaing yang tepat.

Keunggulan bersaing penting untuk diketahui dalam penyusunan perencanaan bisnis karena tidak lepas dari prinsip-prinsip ekonomi, yaitu bagaimana operasional perusahan dapat berjalan lancar dengan meminimalkan seluruh biaya yang ditimbulkan dan memaksimalkan keutungan. Strategi pemasaran merupakan rencana yang menjabarkan ekspetasi perusahan akan dampak dari berbagai aktivitas atau program pemasaran terhadap permintaan produk atau lini produknya di pasar sasaran tertentu. Perusahan dapat menggunakan dua atau lebih program pemasaran secara bersaman, sebab setiap jenis program (seperti periklanan, promosi, penjualan, personal selling, layanan pelanggan, atau perkembangan produk) memiliki pengaruh yang berbeda-beda terhadap permintaan. Oleh sebab itu dibutuhkan mekanisme yang dapat mengkoordinasikan program-program pemasaran agar program-program itu sejalan dan terintegrasi dengan sinergi. Mekanisme ini disebut strategi pemasaran (Tjiptono:283).

PT. Fastrata Buana (FASTANA) sendiri adalah anak perusahan sekaligus dstributor dari produk produk Kapal Api Group. Perusahan holding yang terdiri dari tujuh unit usaha, yaitu Sulotco Jaya Abadi, Santos Jaya Abadi, Agel Langgeng, Fastrata Buana, Excelso multi Rasa, Santos Premium Krimer dan Weiss Tech. Area distribusi dari perusahaan ini menjangkau seluruh wilayah Indonesia dengan produk-produk yang bermutu tinggi. Perusahan gencar memasarkan produknya ke pasaran seperti toko-toko grosir, retailer, dan juga institusi sehingga produk yang ditawarkan oleh PT. Fastrata Buana dikenal luas dan dipercaya oleh masyarakat Indonesia. Produk yang di distribusikan sendiri cukup beragam, yakni Kopi Kapal Api, Kopi ABC, Good Day, Relaxa,dan lain-lain. Produk-produk yang dijual tersebut mungkin sudah tidak asing lagi masyarakat Indonesia karena produk yang dijual tersebut terbilang produk yang cukup popular untuk dikonsumsi masyarakat. Melihat dari kondisi persaingan yang sedemikian 
ketatnya dan perkembangan binis perusahan makanna dan minuman yang semakin maju akhir-akhir ini, membuat penulis tertarik untuk mengadakan penelitian mengenai bisnis makanan. Apalagi PT. Fastrata Buana merupakan perusahan yang mengutaman pelanggan. Penulis juga merasa tertarik dengan penerapan strategi dan ingin meneliti secara lebih mendalam tentang strategi apa yang dijalankan oleh perusahan sehingga dapat bertahan dalam persaingan yang semakin komplek ini.

\section{METODE PENELITIAN}

Metode penelitian penelitian ini menggunakan pendekatan kualitatif. Dalam penelitian ini ada tiga pembahasan yaitu pertama apa strategi pemasaran yang diterapkan oleh PT. Fastrata Buana. Kedua apa keunggulan dari strategi pemasaran yang diterapkan oleh PT. Fastrata Buana. Dan ketiga yaitu strategi pemasaran apa yang baik untuk oleh PT. Fastrata Buana untuk mengatasi persaingan ke depannya. Dengan demikian, dalam rangka untuk mengetahui bagaimana mekanisme strategi bersaing, penting untuk menelusuri lebih dalam bagaimana pengetahuan mengalir, termasuk juga arus pengetahuan yang timbul dari adanya persaingan pemasaran global. Proses yang dilakukan peneliti adalah dengan mendatangi tempat penelitian. Mengamati proses transaksi pemasaran, dan peneliti juga terjun langsung dalam proses transaksi penjualan produk PT. Fastrata Buana 


\section{JURNA \\ ANALISIS, PREDIKSI, DAN INFORMASI}

\section{HASIL DAN PEMBAHASAN}

Informasi pertama pada penelitian ini yaitu peneliti wawancara kepada Ibu Lia selaku manager PT. Fastrata Buana Cabang Krian Sidoarjo. Berikut penjelasan mengenai strategi bersaing yang dijelaskan oleh Ibu Lia kepada peneliti:

a. Strategi pemasaran yang diterapkan oleh PT. Fastrata Buana cabang Krian Sidoarjo yaitu dengan aktif mengembangkan teknik pemasaran retail dengan cara menjual produk-produk kami di pasar atau toko-toko yang ada disekitar Sidoarjo-Surabaya. Selain itu juga PT. Fastrata Buana juga mengembangkan teknik pemasaran secara online yang kini lebih marak dan lebih diminati oleh konsumen yang moyoritas sibuk dan tidak sempat belanja di toko. Belanja secara online pun kini semakin mudah dengan aplikasi yang tersedia di semua sosial media, contohnya di Tokopedia, Shoppe, Facebook maupun di website resmi PT. Fastara Buana. Dan Selain itu juga PT. Fastrata Buana juga mengembangkan pemasarnnya dengan semi grosir ke toko besar atau agen di sekitar Surabaya-Sidoarjo.

b. Keunggulan dari strategi pemasaran yang diterapkan oleh PT. Fastrata Buana yaitu perusahaan selalu mengedepankan kualitas pelayanan dengan distribusi dengan baik kepada semua konsumen PT. Fastrata Buana Cabang Krian Sidoarjo.

c. Strategi pemasaran yang baik oleh PT. Fastara Buana Cabang Krian Sidoarjo untuk mengatasi persaingan kedepannya yaitu dengan lebih menonjolkan iklan, seperti iklan yang ada TV, Youtube, Radio, Media sosial, dll agar dapat mengatasi persaingan pemasaran global yang saat ini perusahan competitor sangat berlombalomba untuk mengedepankan distribusi nya di masyarakat. Contoh iklan yang dapat memberikan dampak positif ke PT. Fastara Buana Cabang Krian Sidoarjo yaitu dengan memasang spanduk atau banner di toko atau agen dan juga memasang di tempat yang strategis,serta memberikan hadiah ke pada konsumen atau agen yang telah bekerja sama di PT Fastara Buana Cabang Krian contohnya seperti hadiah tiket 
liburan ke dalam atau luar negeri, hadiah mug atau gelas cantik, kaos, discount besar besaran. Dan PT. Fastara Buana lebih mengedepankan pemasaran iklan secara online atau belanja online dengan mudah dan praktis agar dapat dijangkau di seluruh Indonesia maupun Internasional.

\section{KESIMPULAN DAN SARAN}

\section{Kesimpulan}

Dalam penelitian ini, dapat disimpulkan bahwa PT. Fastrata Buana Cabang Krian Sidoarjo selalu mengedepankan loyalitas dalam transaksi penjualan yang selalu ramah dan sopan satun kepada setiap konsumen karena kepuasan konsumen adalah prinsip perusahaan ini. Srategi pemasaran yang kini dilakukan di PT. Fastrata Buana adalah meembuat iklan yang semenarik mungkin iklan yang akan ditayangkan. Dengan iklan yang semenarik mungkin dan bermanfaat, maka akan menjadikan iklan tersebut menjadi panutan kepada masyarakat yang melihat. Melihat strategi pemasaran yang semakin banyak dan canggih di perusahaan competitor, maka perusahan PT. Fastara Buana Cabang Krian juga tidak mau kalah. Hal ini dibuktikan dengan semakin banyak nya iklan Produk Kapal Api Group di berbagai tempat, contohnya iklan di Youtube, TV, Radio, banner dan spanduk disemua tempat, dll. PT. Fastara Buana Cabang Krian Sidoarjo juga memberikan motivasi kepada semua karyawannya terutama kepada karywan seles untuk selalu bersemangat dalam berjualan dan memberikan kontribusi kepada semua masyarakat atau pelanggan.

\section{Saran}


Berdasarkan kesimpulan diatas dan hasil penelitian yang dilakukan, terdapat beberapa hal yang perlu diperhatikan dan diharapkan dapat menjadi bahan pertimbangan untuk langkahlangkah selanjutnya, yaitu :

1. Bagi perusahaan hendaknya selalu meningkatkan pertumbuhan penjualan agar perusahaan menjadi lebih baik lagi.

2. Melihat hasil analisis secara keseluruhan, PT. Fastara Buana Cabang Krian Sidoarjo telah memberikan kontribusi yang sangat baik kepada karyawan maupun pelanggan dengan memberikan suatu penghargaan atau bonus yang membuat semakin gigih dalam berjualan produk-produk Kapal Api. Karena tidak semua karyawan di perusahaan lain mendapkan hadiah atau bonus.

3. Bagi peneliti lain diharapkan dapat melengkapai kekurangan yang ada dalam penelitian ini, sehingga ilmu pengetahuan tentang pemasaran dan dapat dikembangkan apabila ada penelitian selanjutnya.

\section{DAFTAR PUSTAKA}

Alma, B. 2003. Strategi pemasaran. Jurnal EMBA.

Djaslim, Saladin. 2011. Manajemen Pemasaran Bandung. Agung Ilmu.

Badriyah, N., Siswanto, S., \& Ishaq, I. (2020). Strategi Relational Benefit Terhadap Peningkatan Kepuasan Pelanggan Pada Alvira Mart Tikung Lamongan. Jurnal Sains Sosio Humaniora, 4(1), 189-193.

Jubaidah, Irani. 2019. Pengaruh Strategi Pemasaran Terhadap Keunggulan Bersaing Pada Lazis Muhamadiyah Surabaya.

\section{DJ, Y. R. (2017). ANALISIS PENGARUH EXPERIENTIAL MARKETING TERHADAP LOYALITAS PELANGGAN (STUDY KASUS DI CV. LAMONGAN SPORTS CENTER). JPIM (Jurnal Penelitian Ilmu Manajemen), 2(3), 8-Halaman.}


DJ, Y. R. (2019). PENGARUH KUALITAS PRODUK DAN PROMOSI TERHADAP KEPUTUSAN PEMBELIAN PRODUK SMARTPHONE OPPO. Media Mahardhika, 17(3), 463-466.

Hasiholan, L. B., \& DJ, Y. R. (2019). Strategi Positioning Dalam Upaya Membangun Brand. Jurnal Penelitian IPTEKS, 4(2), 229-240.

Dj, Y. R., Rosyad, S., \& Muhtarom, A. (2019). Determination of Development of Small Micro Business that Enforces Deket Village, Lamongan Indonesia District. Int $J$ Res Manag Econ Commer, 9(6), 27-29.

Edy, I. T., Badriyah, N., Khilil, M. U., \& Iskandar, I. (2020). Pengaruh Kualitas Dan Kinerja Pelayanan KTP Elektronik Terhadap Kepuasan Masyarakat Terhadap Dinas Kependudukan dan Pencatatan Sipil Kabupaten Lamongan. Jurnal Sains Sosio Humaniora, 4(2), 937-941.

Kotler, Philip and Kevin Lane Keller, 2016. Marketing Management, 15thn Global Edition, Pearson Prentice Hall. New Jersey.

Lubis, Z., Mauladi, K. F., \& Irawan, M. R. N. (2020). PENENTUAN STRATEGI PEMASARAN DALAM MEMPERTAHANKAN EKSISTENSI DAN MENGADAPI PERSAINGAN (Studi Kasus Pada Gemilang Art Glass Di Modo). Media Mahardhika, 19(1), 59-70.

Lilis, Wahidatul 2018. Strategi Pemasaran Dalam Meningkatkan Penjualan Tahubaxo Ibu Pudji Ungaran Dalam Perspektif Ekonomi Islam.

Lucky, Radi Rinandiya., Ane, Kurniawati,. 2016. Strategi Untuk meningkatkan Keungulan Bersaing Melalui Pengembangan, Desain, dan Kualitas Produk (Studi Kasus Pada Industri Pakaian Muslim di Kota

Ristyanadi, B., \& Jayanti, Y. R. D. (2018). Pengaruh Citra Merk Dan Kepuasan Pelanggan Terhadap Loyalitas Konsumen (Studi kasus Perilaku Konsumen Toko Roti Lyly Bakery). JPIM (Jurnal Penelitian Ilmu Manajemen), 3(2), 690-702. 


Rajawali Nusindo Cabang Medan.

